\title{
Symptoms and investigative findings in 145 patients with tuberculous peritonitis diagnosed by peritoneoscopy and biopsy over a five year period
}

\author{
A Manohar, A E Simjee, A A Haffejee, K E Pettengell
}

\begin{abstract}
This study analysed clinical features and laboratory investigations in 145 patients with tuberculous peritonitis diagnosed by peritoneoscopy at this hospital between 1984 and 1988. Tuberculous peritonitis was found in $2 \%$ of all patients with tuberculosis and in $59.8 \%$ of all those with abdominal tuberculosis admitted to the hospital during the study period. Tuberculous peritonitis was more common in women than men (1.4:1) and was most frequently encountered in the third and fourth decades of life. The commonest presenting symptoms were abdominal swelling (73.1\%), fever and night sweats $(53.8 \%)$, anorexia $(46.9 \%)$, weight loss $(44.1 \%)$, and abdominal pain $(35.9 \%)$. The mean duration of symptoms was 1.5 months. Ascites was the commonest $(95 \cdot 2 \%)$ physical sign. Tuberculin skin testing was positive in $57.6 \%$ of patients $(n=118)$. The mean erythrocyte sedimentation rate was $75 \mathrm{~mm} / 1$ st hour $(n=58)$. Chest radiography on 98 patients showed pleuropulmonary pathology in $\mathbf{4 0}$ patients $(\mathbf{4 0} \cdot \mathbf{8} \%)$. Sputum examination confirmed active pulmonary tuberculosis in 26 patients. The ascitic fluid was an exudate in $96.4 \%$ and a transudate in $3.6 \%$ of patients, with $91.3 \%$ showing a straw coloured ascites. Cirrhosis, detected by biopsy specimen, was a finding in $6 \cdot 2 \%$ of patients.
\end{abstract}

Abdominal tuberculosis may affect the gastrointestinal tract, peritoneum, or abdominal lymph nodes (mesenteric or retroperitoneal). While it has become an uncommon disease in the western world, it remains an important source of patient morbidity in developing countries. Tuberculous peritonitis is the commonest form of abdominal tuberculosis. ${ }^{2}$ The incidence of tuberculous peritonitis ranges from $0 \cdot 1 \%$ to $0.7 \%$ of all reported cases of tuberculosis. ${ }^{3}$

King Edward VIII Hospital is perhaps the only centre in South Africa where peritoneossuspected tuberculous peritonitis. This study was performed to analyse this unique experience.

(Gastrointestinal unit) and Surgery, University of Natal/King Edward VIII Hospital, Durban, South Africa A Manohar

A E Simiee

A A Haffejea

K E Pettengell

Correspondence to:

Dr A Manohar,

Gastrointestinal Unit,

Department of Medicine,

PO Box 17039, Congella, 4013, South Africa.
40 17039, Congent

Accepted for publication

1 December 1989

\section{Patients and methods}

The peritoneoscopy records (from 1 January 1984 to 31 December 1988) of patients seen at the gastrointestinal unit, of this hospital were reviewed. At King Edward VIII Hospital peritoneoscopy is performed routinely under local anaesthesia and the procedure is only rarely undertaken in children. Hence only those reports on patients over the age of 12 years were copy is used routinely in the investigation of

reviewed. The case notes of those patients in whom tuberculous peritonitis had been shown in biopsy specimens were then analysed. Clinical features at presentation and the results of laboratory investigations were collated. The diagnosis of tuberculous peritonitis was made histologically on the presence of granulomata with caseation or acid fast, bacilli, or both.

\section{Results}

Peritoneoscopy was performed on 894 patients during the study period. There were 145 patients with tuberculous peritonitis: 142 were African and three were Indian. Tuberculous peritonitis was found in $2 \%$ of all patients with tuberculosis and in $59 \%$ of those with abdominal tuberculosis admitted to this hospital. The predominant age group for tuberculous peritonitis was 20-39 years $(48 \cdot 2 \%)$; the mean age for women was 32 years and that for men was 39 years. Ages ranged from 14 to 78 years. There were $84(57 \cdot 9 \%)$ women and $61(42 \cdot 1 \%)$ men with a female to male ratio of $1 \cdot 4: 1$.

\section{CLINICAL FEATURES}

The mean duration of clinical symptoms was 1.5 months, with a range of one week to six months. Symptoms at presentation are shown in Table I. The commonest physical sign was ascites $(95 \cdot 2 \%)$; the remainder $(4 \cdot 8 \%)$ presented with a 'doughy' abdomen.

\section{LABORATORY INVESTIGATIONS}

Tuberculin skin testing using purified protein derivative was positive ( $>14 \mathrm{~mm}$ ) in $57.6 \%$ of patients $(n=118)$. The mean erythrocyte sedimentation rate was $75 \mathrm{~mm} / \mathrm{lst}$ hour $(\mathrm{n}=58)$ with a range of 5 to $155 \mathrm{~mm} / \mathrm{lst}$ hour (Table II). Haematological investigations $(n=145)$ showed a mean haemoglobin concentration of $11 \mathrm{~g} / \mathrm{dl}$ (range 6-15 g/dl), a mean total white cell count of
TABLE I Symptoms (\%) of patients with tuberculous peritonitis $(T P)$

\begin{tabular}{|c|c|c|c|}
\hline & $\begin{array}{l}\text { TP alone } \\
(n=119)\end{array}$ & $\begin{array}{l}T P+P T B^{\star} \\
(n=26)\end{array}$ & $\begin{array}{l}\text { Total } \\
(n=145)\end{array}$ \\
\hline $\begin{array}{l}\text { Abdominal swelling } \\
\text { Fever/night sweats } \\
\text { Anorexia } \\
\text { Weight loss } \\
\text { Abdominal pain } \\
\text { Diarrhoea } \\
\text { Constipation } \\
\text { Pulmonary symptoms }\end{array}$ & $\begin{array}{r}73 \cdot 9 \\
47 \cdot 1 \\
43 \cdot 7 \\
40 \cdot 3 \\
36 \cdot 1 \\
13 \cdot 4 \\
6 \cdot 7 \\
12 \cdot 6\end{array}$ & $\begin{array}{l}69 \cdot 2 \\
84 \cdot 6 \\
61 \cdot 5 \\
61 \cdot 5 \\
34 \cdot 6 \\
11 \cdot 5 \\
3 \cdot 8 \\
96 \cdot 2\end{array}$ & $\begin{array}{l}73 \cdot 1 \\
53 \cdot 8 \\
46 \cdot 9 \\
44 \cdot 1 \\
35 \cdot 9 \\
13 \cdot 1 \\
6 \cdot 2 \\
27 \cdot 6\end{array}$ \\
\hline
\end{tabular}

$\star \mathrm{PTB}=$ active pulmonary tuberculosis (diagnosed on sputum examination). 
TABLE II Erythrocyte sedimentation rate in 58 patients with tuberculous peritonitis

\begin{tabular}{cc}
\hline Value $(\mathrm{mm} / \mathrm{hr})$ & No $(\%)$ of patients \\
\hline$<10$ & $2(3 \cdot 4)$ \\
$10-39$ & $13(22 \cdot 4)$ \\
$40-69$ & $15(25 \cdot 9)$ \\
$70-99$ & $13(22 \cdot 4)$ \\
$100-129$ & $6(10 \cdot 4)$ \\
$130-160$ & $9(15 \cdot 5)$ \\
\hline
\end{tabular}

$8 \times 10^{9} / 1$ (range $2 \cdot 2-19 \cdot 8 \times 10^{9} / 1$ ), and a mean platelet count of $384 \times 10^{9} / 1$. Table III shows the distribution of these values. Chest radiography. on 98 patients showed pleuropulmonary abnormalities in $40(40 \cdot 8 \%)$. Sputum examination confirmed active pulmonary tuberculosis in 26 of these patients.

The ascitic fluid was straw coloured in $91.3 \%$ and blood stained in $8 \cdot 7 \%$ of patients $(n=138)$. In no patient were acid fast bacilli detected in the small quantities of ascitic fluid removed for examination. The ascites was an exudate (total protein $\geq 30 \mathrm{~g} / \mathrm{l}$ ) in $96.4 \%$ and a transudate in $3.6 \%$ of patients, with a mean protein content of $48 \mathrm{~g} / \mathrm{l}$ (range $18-68 \mathrm{~g} / \mathrm{l}$ ). Peritoneoscopy findings consisted of typical peritoneal tubercules in 142 patients and scattered erythematous patches in three patients. Histology of peritoneal biopsy specimens showed granulomata with caseation in all patients, with acid fast bacilli being found in $107(73.8 \%)$ patients. Hepatic cirrhosis proved by biopsy specimen was present in nine patients $(6 \cdot 2 \%)$.

\section{Discussion}

Previous studies ${ }^{2-12}$ of tuberculous peritonitis have been influenced by either small patient numbers ${ }^{2-4}$ or long review periods. ${ }^{67}$ Small numbers of patients meant results and conclusions had to be treated with reserve. Prolonged review periods, decades in some cases, influenced the analysis because of advances in diagnostic techniques and treatments. It was hoped that this study would overcome these limitations.

The racial distribution of tuberculous peritonitis (African/Indian=47:1) is three times the ratio for general admissions to this hospital. It is, however, less than the racial ratio for admission of all patients with tuberculosis $(65: 1)$.

This study confirms the findings of other reviews ${ }^{2-12}$ that tuberculous peritonitis has a female predominance and is most common in the third or fourth decade of life. Table IV shows the cumulative data of symptoms collected from six published series ${ }^{2-46-9}$ compared with those in this

TABLE III Haematological investigations in patients with tuberculous peritonitis

\begin{tabular}{lc}
\hline $\begin{array}{l}\text { Haemoglobin }(\mathrm{g} / \mathrm{dl}) \\
\text { Normal }\end{array}$ & No $(\%)$ of patients \\
Anaemia & $58(40)$ \\
White cell count $\left(\times 10^{\circ} / \mathrm{l}\right)$ & $87(60)$ \\
$<4$ & $13(9)$ \\
$4-11$ & $116(80)$ \\
$>11$ & $16(11)$ \\
Platlets $\left(\times 10^{\circ} / 1\right)$ & $5(3.4)$ \\
$<150$ & $76(52 \cdot 4)$ \\
$150-400$ & $49(33 \cdot 8)$ \\
$400-650$ & $15(10 \cdot 4)$ \\
$650-900$ & \\
\hline
\end{tabular}

^Haemoglobin $<13.5 \mathrm{~g} / \mathrm{dl}$ in men and $<12.5 \mathrm{~g} / \mathrm{dl}$ in women.
TABLE IV Cumulative data of symptoms from six series

\begin{tabular}{lll}
\hline & Previous series (\%) & Present series (\%) \\
\hline Abdominal swelling & 72 & $73 \cdot 1$ \\
Fever/night sweats & 57 & $53 \cdot 8$ \\
Anorexia & $44 \cdot 3$ & $46 \cdot 9$ \\
Weight loss & $55 \cdot 6$ & $44 \cdot 1$ \\
Abdominal pain & 70 & $35 \cdot 9$ \\
Diarrhoea & 16.4 & 13.1 \\
Constipation & 19.6 & 6.2 \\
\hline
\end{tabular}

study. While most of the symptoms occurred with comparable frequencies, abdominal pain was a significantly $(p<0.001)$ less common complaint in this study. The mean duration of clinical symptoms in our experience was shorter than in three previous series -1.5 months compared with a mean of three months. ${ }^{467}$

Past reviews ${ }^{2-12}$ have not made a distinction between symptoms caused by tuberculous peritonitis alone and those that could be attributable to coexistent pulmonary tuberculosis. When the symptoms in patients with and without pulmonary tuberculosis are studied separately (Table II), it can be seen that the presence of coexistent pulmonary tuberculosis significantly increases the frequency of fever and night sweats, weight loss, and pulmonary symptoms encountered ( $p<0.001 ; 0.05$; and 0.001 respectively).

It has been stated that peritoneal tuberculosis is usually secondary to a focus elsewhere in the body. ${ }^{8}$ In the present series, however, active pulmonary disease was present in only $17 \cdot 9 \%$ of patients. This parallels the situation found today with intestinal and pulmonary tuberculosis and emphasises that a normal chest radiograph does not mitigate against a diagnosis of either form of abdominal tuberculosis.

Tuberculous peritonitis manifests itself in two ways:

(a) Exudative or moist type with ascites.

(b) Plastic or dry type resulting in the typical 'doughy' abdomen.

As in two previous reviews ${ }^{28}$ this study confirms that the ascitic type is commonest $(95 \cdot 2 \%)$ with the plastic type being a rare clinical entity.

Routine biochemical investigations are usually unhelpful in the diagnosis of tuberculous peritonitis. ${ }^{2-12}$ A strongly positive Mantoux and a noticeably raised erythrocyte sedimentation rate, although suggesting tuberculous peritonitis, are by themselves non-specific. Also, patients with tuberculous peritonitis may have a negative Mantoux (42.4\%) and a normal erythrocyte sedimentation rate $(3 \cdot 4 \%)$.

Previous studies of tuberculous peritonitis ${ }^{2-12}$ have not analysed haematological investigations as set out in Table III. Anaemia, which occurred in $60 \%$ of patients, was usually a normochromic normocytic anaemia of chronic infection. Leucocytosis was more common than leucopaenia in our study $(11 \% v 9 \%)$ than in another report. ${ }^{2}$ Thrombocytosis was a frequent finding in this series $(44 \cdot 2 \%)$. This confirms an association between tuberculosis and raised platelet counts. ${ }^{1314}$

Ascitic fluid analysis is not usually of specific diagnostic value since acid fast bacilli are rarely found' when small volumes of ascitic fluid are examined, as in this study. An exudative ascites, 
however, may be suggestive of tuberculous peritonitis in an endemic area and provide sufficient ground for treatment. This study has shown that peritoneoscopy can provide a reliable means of confirming the disease histologically. A surprising finding of this series, not previously reported, was the finding of acid fast bacilli in peritoneal biopsy specimens of three patients showing only mild peritoneal erythema. This emphasises the need for taking a biopsy specimen of these lesions when they are found.

In view of the relatively high incidence of cirrhosis among black South Africans, the association between cirrhosis and tuberculous peritonitis was surprisingly low in this study. The association between cirrhosis and tuberculous peritonitis has been the subject of interest in many previous retrospective studies. ${ }^{7-11}$ This association is important as tuberculous peritonitis may be missed in a patient known to have cirrhosis and who now presents with ascites. Ascitic fluid analysis in cirrhotic ascites and tuburculous ascites may be similar. As in this and other studies, however, the presence of fever, abdominal pain, and abdominal tenderness in a cirrhotic patient points to the presence of a coexistent second abnormality such as tuberculous peritonitis.

In conclusion, retrospective studies of tuberculous peritonitis are helpful in alerting the physician to the typical clinical profile of these patients. With the advent of peritoneoscopy, a more definitive diagnosis of tuberculous peritonitis can be made, provided one has a high index of clinical suspicion.
We acknowledge the assistance of Miss L Moodley (funded by the Ford Foundation) for data collection. We also thank Dr . Dr Manohar is a post-intern research scholar sponsored by the Dr Manohar is a post-intern research schol
South African Medical Research Council.

1 Kapoor VK, Sharma LK. Abdominal Tuberculosis. Br f Surg 1988; 75: 2-3

2 Gilinksky NH, Marks IN, Kottler RE, Price SK. Abdominal Tuberculosis: a 10 -year review. $S$ Afr Med $\mathcal{f} 1983$; 64: 849-57.

3 Vyravanathan S, Jeyarajah R. Tuberculous Peritonitis: a Review of Thirty-Five Cases. Postgrad Med $\mathcal{F}$ 1980; 56: 649-51.

4 Bastani B, Shariatzadeh MR, Dehdashti F. Tuberculous Peritonitis: report of 30 cases and review of the literature. QF Med 1985; 56: 549-57.

5 Singh MN, Bhargava AN, Jain KP. Tuberculous peritonitis: an evaluation of pathogenetic mechanisms, diagnostic pro$1091-4$.

6 Dineen P, Homan WP, Grafe WR. Tuberculous peritonitis: 43 years experience in diagnosis and treatment. Ann Surg

7 Burack WR, Hollister RM. Tuberculous peritonitis. A study of forty-seven proved cases encountered by a general medical unit in twenty-five years. Am $\mathcal{F}$ Med 1960; 28: 510-23.

8 Bettarello A, Polak M. Tuberculous peritonitis. G I report 1987; 2: 1-7.

9 Reddy KR, Di Prima RE, Raskin JB, et al. Tuberculous peritonitis: laparoscopic diagnosis of an uncommon disease in the United States. Gastrointest Endosc 1988; 34: 422-6.

10 Geake TMS, Spataels JM, Moshal MG, Simjee AE. Peritoneoscopy in the Diagnosis of tuberculous peritonitis. Gastrointest Endosc 1981; 27: 66-8.

11 Nafeh MA, Shahwan MM, Mohammed SS, Rashwan NM Endoscopic Diagnosis of ascites in assiut province, upper Endoscopic Diagnosis of ascites in assiut province, upper Egypt. Endoscopy 1983; 15: 347-9.

12 Sochodky S. Tuberculous peritonitis. Am Rev Respir Dis 1967; 95: 398-401.

13 Jacobs P. The haematology of tuberculosis. S Afr Med $\mathcal{F} 1989$; 75: 98-9.

14 Baynes RD, Bothwell TH, Flax H, et al. Reactive thrombocytosis in pulmonary tuberculosis. $\mathcal{f}$ Clin Pathol 1987; 40: 676-9. 